\title{
The Disparity in Transit Travel Time between Koreans and Japanese in 1930s Colonial Seoul
}

\author{
Youngjoon $\mathrm{Kim}^{1}$ (D), Jinhyung Lee ${ }^{2}$ (D) Junghwan $\mathrm{Kim}^{3}$ (D), Naoto Nakajima ${ }^{1}$ \\ ${ }^{1}$ Department of Urban Engineering, The University of Tokyo, Tokyo, Japan, 2 Department of Geography and Environment, Western University, London, Ontario, \\ Canada, ${ }^{3}$ Center for Geographic Analysis, Institute for Quantitative Social Science, Harvard University, Cambridge, MA, USA \\ Keywords: colonial urban planning, digital humanities, disparity, gtfs, public transit, seoul \\ https://doi.org/10.32866/001c.25226
}

Findings

Transportation is a key element to understanding the socio-spatial structure of colonial cities and the lives of individuals living under colonial governance. This study investigates the disparity in transit-based travel time between colonial rulers (Japanese) and subjects (Koreans) in Colonial Seoul (Keijo) in 1936 using modern GIS and open-source transport analysis tools. Findings suggest a significant disparity in travel time to a major urban facility (i.e., City Hall) between the two population groups of the largest colonial city in the Korean peninsula.

\section{Questions}

Transport is a key element to understanding the socio-spatial structure of urban areas (Kawabata and Shen 2006). However, a nuanced understanding of transport geography and planning in colonial cities has been limited due to the lack of integrated research methods such as digital humanities (e.g., Donnellan 2019). Most previous studies on transport in colonial cities have adopted solely qualitative approaches, such as content analysis of historical newspaper articles (e.g., Hazareesingh 2001). Recent advancements in digital technologies and open-source analysis tools provide unprecedented opportunities for researchers to understand transport in the distant past.

This study aims to demonstrate the capabilities of GIS and transport analysis toolkits for understanding the disparity in transit-based travel time between Koreans (i.e., colonial subjects) and Japanese (i.e., colonial rulers) in Colonial Seoul (officially Keijo by the Japanese Governor-General of Colonial Korea) in 1936.

Specifically, we ask the following two research questions:

- How can we use GIS and transport analytics tools to measure transitbased travel time in Colonial Seoul (Keijo)?

- How does transit-based travel time differ between Japanese (colonial rulers) and Koreans (colonial subjects)?

Answering these questions would significantly contribute to the literature of colonial cities by providing broader insights into disparities in travel time via public transit networks. 
(a)

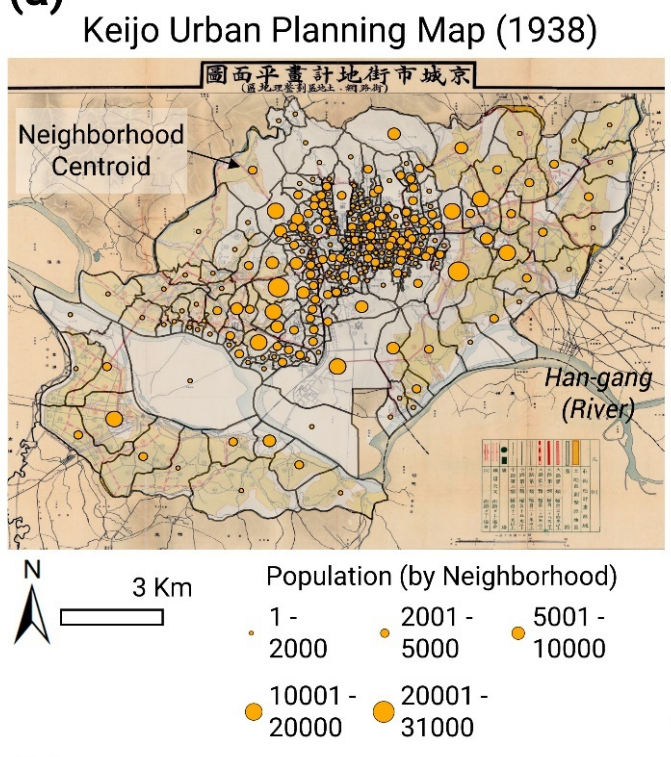

(b)

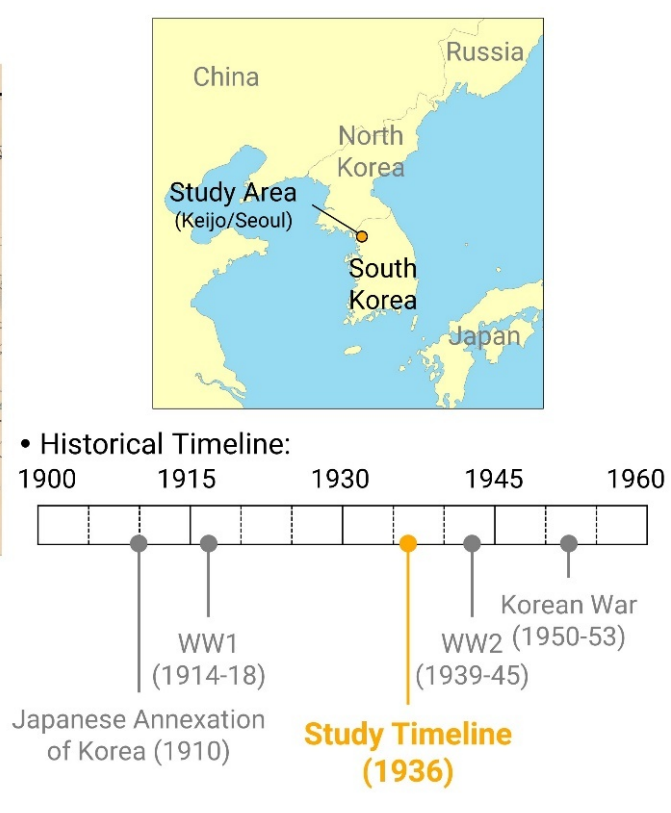

- Key Historical Materials:
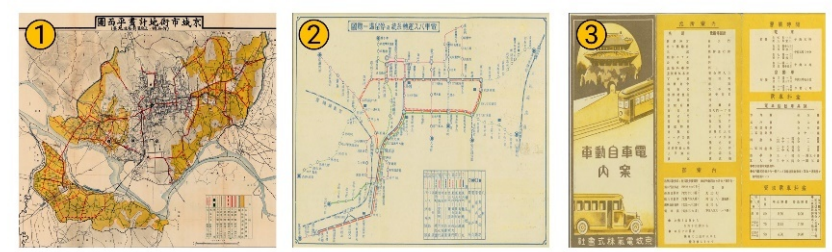

(1) Keijo Urban Planning Map (1938)

(2) Keijo Tram and Bus Route Map

(3) Keijo Tram and Bus Operation Information (e.g., headway)

- Method:

\begin{tabular}{|c|c|c|} 
Digitizing and \\
Georeferencing
\end{tabular}$\rightarrow \begin{gathered}\text { GTFS Data } \\
\text { Preparation } \\
(\text { RTAP's GTFS Builder) }\end{gathered} \rightarrow \begin{gathered}\text { Travel Time } \\
\text { Estimation }(r 5 r)\end{gathered} \rightarrow \begin{gathered}\text { Analysis and } \\
\text { Mapping }\end{gathered}$

Figure 1. (a) Study area and timeline; (b) Key historical materials and research design.

Note: Keijo indicates Colonial Seoul.

\section{Methods}

We focused on Keijo in 1936 (Figure 1) when it was experiencing a massive expansion of its administrative boundaries and explosive population growth. Serious transport issues (e.g., congestion) began in the early 1930s as the number of transit passengers increased dramatically and Japanese monopolized the supply and operation of the public transport system of Keijo (e.g., Choi and Kim 2013).

Two main data sources were used for generating 1) administrative boundaries and 2) public transit networks. First, we georeferenced Keijo Urban Planning Map (1938) and The Map of Greater Keijo (1936) to digitize the administrative boundaries of 258 neighborhoods (called "Dong") in the study area. We also used the Keijo Occupational Census dataset, surveyed in 1936, to populate the digitized administrative units. The total number of Koreans is 541,737, and that of Japanese is 126,673. These datasets were provided by Seoul Museum of History and the National Library of Korea. 
Next, in order to construct the public transit network of Keijo, we first digitized the Keijo Tram and Bus Route Map (mid-1930s), integrated transit schedule information to the digitized network, and finally generated a General Transit Feed Specification (GTFS) dataset for the city of Keijo. We used the National Rural Transit Assistance Program (RTAP) GTFS Builder to build the GTFS dataset (U.S. Department Transportation 2021).

Using the GTFS dataset as a basis, we leveraged an open-source transport analysis tool - r5r R-package (Pereira et al. 2021) - to estimate total transit travel times as well as out-of-vehicle walking/waiting times, which are important factors for measuring transit-based accessibility (Kim and Lee 2019; Lee and Miller 2020). We also used the $r 5 r$ toolkit to measure variances in travel times from each neighborhood unit to City Hall within a two-hour time window (6-8 AM). $r 5 r$ computed travel times from centroids of 258 neighborhood to City Hall at $6 \mathrm{AM}$ and every minute for 2 hours after. The maximum walking distance was assumed as 3,500 meters, according to the maximum distance between each centroid to the nearest tram or bus station. Travel times retrieved at different points (e.g., 5-percentile, 95-percentile) of the distribution were used to assess each neighborhood's travel time variation.

\section{Findings}

Figures 2(a) and (b) illustrate the Korean-Japanese population ratio and total travel times, respectively. Note that 27 trips were excluded as they were not made by transit (i.e., walking only). Figure 2(a) also highlights that, after the Japanese Annexation of Korea in 1910, most new public transit systems (black lines) in Keijo were added to support Japanese people's mobility. Specifically, added route-meter-per-population of Korean and Japanese populations are 0.21 and 0.72, respectively. Figures 2 (c) and (d) illustrate the out-of-vehicle walking and waiting times, respectively. The higher out-of-vehicle walking time indicates that people walked longer distances to/from the stations. The higher out-of-vehicle waiting time indicates that public transit services were less frequent. Welch's t-tests were conducted to examine whether there were significant differences in these travel time variables between Japanese- and Korean-dominant neighborhoods ( $\underline{\text { Table 1 }}$ ). Results indicate that the averages of total travel time, out-of-vehicle walking time, and out-of-vehicle waiting time were significantly higher for Koreans than for Japanese, demonstrating disparities in transit-based travel time between the two population groups.

Figure 3(a) is an isochrone of the total travel time to City Hall. It demonstrates that southern Keijo had shorter travel times (i.e., better access) to City Hall (compared to other areas at a similar distance). This is because Japanese rulers had settled in these areas and built new tram lines to meet their mobility needs.

Figure 3(b) illustrates the variations in travel time from each neighborhood to City Hall within the 6-8 AM time window. A longer vertical bar indicates a higher variation in travel time from a neighborhood to the destination at the 
(a)

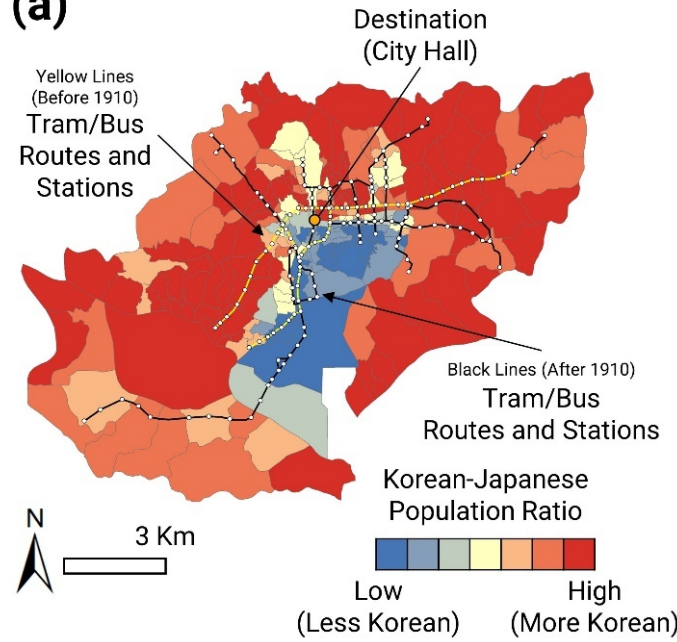

(c)

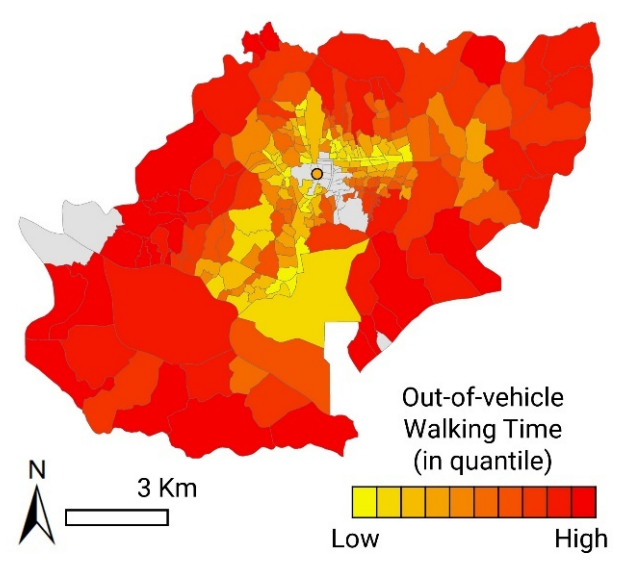

(b)

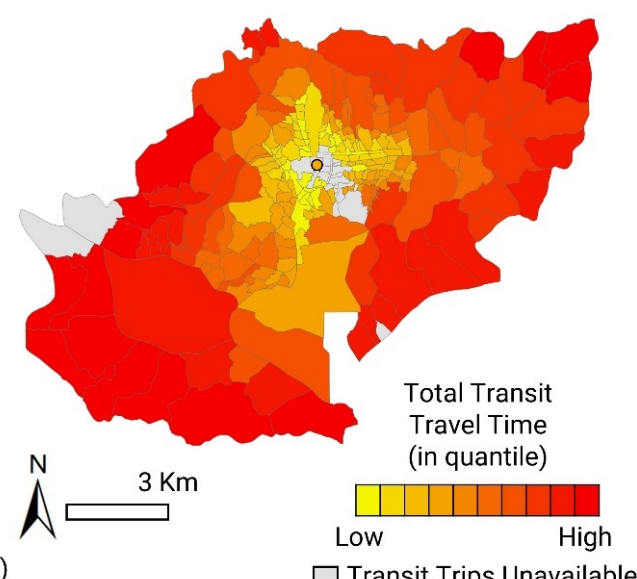

(d)

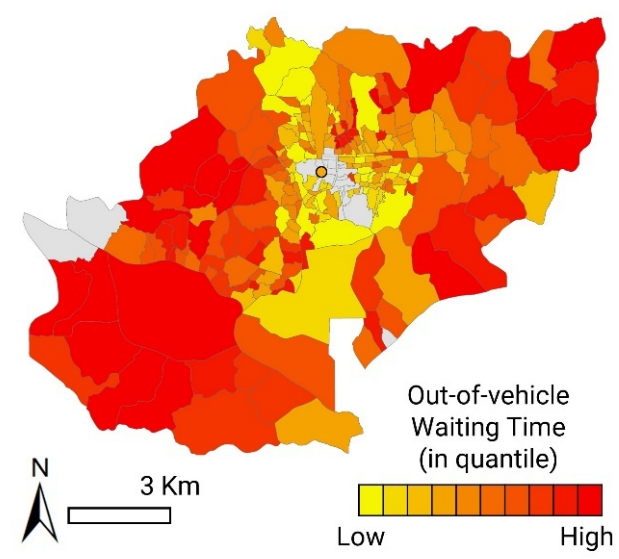

Figure 2. (a) Korean-Japanese population ratio; (b) total travel time; (c) out-of-vehicle walking time; (d) out-of-vehicle waiting time.

Table 1. Comparison of total travel times and out-of-vehicle walking/waiting times between Japanese- and Korean-dominant neighborhoods.

\begin{tabular}{|c|c|c|c|c|}
\hline & & Total Travel Time & Walking Time & Waiting Time \\
\hline \multirow{4}{*}{ Japanese-dominant Neighborhood $(n=42)$} & Mean (min) & 22.458 & 14.083 & 2.446 \\
\hline & SD & 7.429 & 7.920 & 1.566 \\
\hline & $\operatorname{Min}(\min )$ & 8.750 & 1.850 & 0.033 \\
\hline & $\operatorname{Max}(\min )$ & 44.383 & 38.850 & 6.050 \\
\hline \multirow{4}{*}{ Korean-dominant Neighborhood $(n=189)$} & Mean (min) & 36.006 & 19.889 & 4.376 \\
\hline & SD & 21.058 & 14.393 & 3.478 \\
\hline & $\operatorname{Min}(\min )$ & 7.750 & 1.933 & 0.000 \\
\hline & $\operatorname{Max}(\min )$ & 91.783 & 59.767 & 32.283 \\
\hline Welch's $t$-test & & $* * *$ & $* * *$ & $* * *$ \\
\hline
\end{tabular}

Note: ${ }^{* * *}$ denotes $p<0.001$. 
(a)

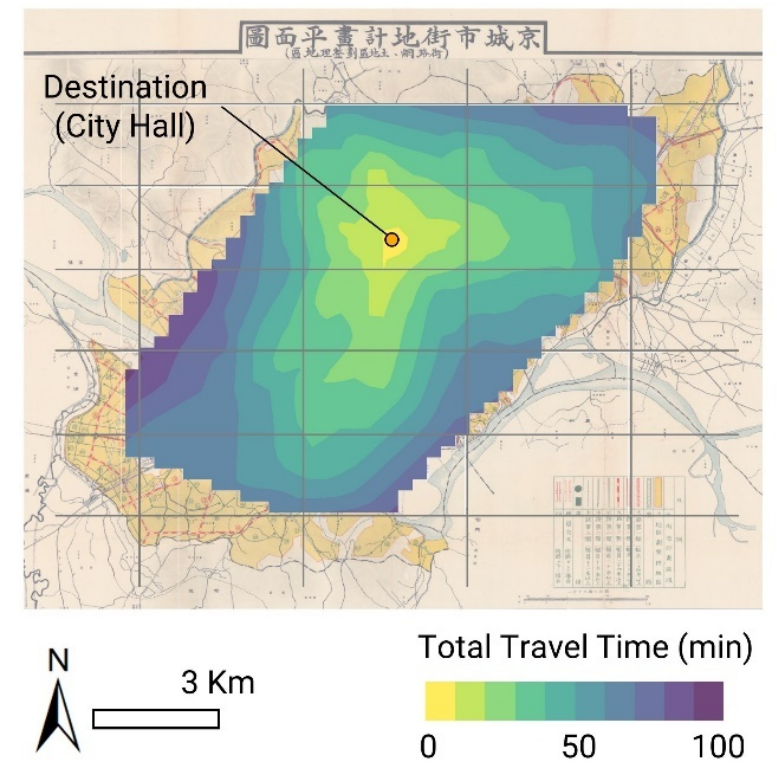

(b)

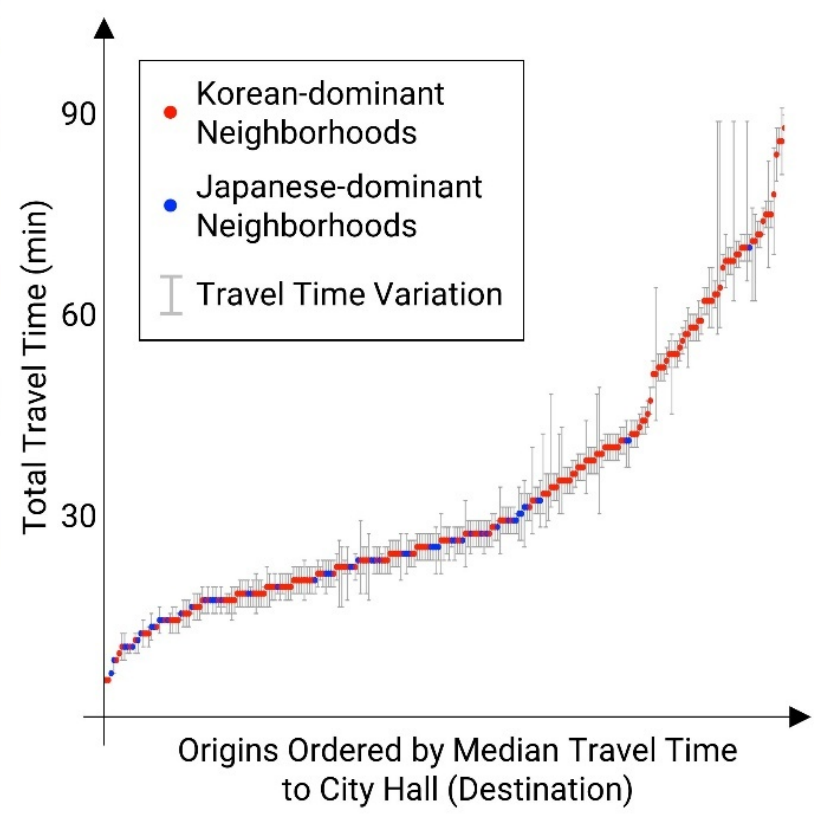

Figure 3. (a) Isochrone of total travel time to City Hall; (b) Travel time variation of Korean-dominant and Japanesedominant neighborhoods.

Table 2. Mean travel time variance of Japanese- and Korean-dominant neighborhoods.

\begin{tabular}{lll}
\hline & Mean of travel time variance $(\min )$ & Median of travel time variance (min) \\
\hline Japanese-dominant Neighborhood $(\mathrm{n}=42)$ & 3.29 & 4 \\
\hline Korean-dominant Neighborhood $(\mathrm{n}=189)$ & 5.50 & 4 \\
\hline$t$-test & $* * *$ & - \\
\hline
\end{tabular}

Note: ${ }^{* * *}$ denotes $\mathrm{p}<0.001$.

given time window. This figure demonstrates that the travel time variations of Korean-dominant neighborhoods (red dots) are generally larger than those of Japanese-dominant neighborhoods (blue dots).

The mean travel time variance of Korean- and Japanese-dominant neighborhoods is 5.50 and 3.29 minutes, respectively (Table 2). The $t$-test confirms that the mean of travel time variance is significantly higher for Koreans than for Japanese.

Overall, our findings demonstrate the significant disparity in transit-based travel time between colonial rulers and subjects. Although previous qualitative studies reported similar results (e.g., Choi 2010; Kim 2007), their findings did not provide a more comprehensive understanding of colonial cities' transport issues, such as the disparity in travel time. Our research fills the gap by providing a broader yet more detailed picture of historical public transit issues 
using GIS and open-source transport analysis tools. Our findings also manifest the significant potential of digital humanities methods for understanding historical urban transport issues, especially in colonial cities around the globe.

\section{Acknowledgement}

This work is partially supported by the Faculty of Social Science and Western SSHRC Success Seed Grant at Western University. The authors thank Jihaeng Lee for his excellent research assistantship in digitizing historical maps. We also appreciate Seoul Museum of History and the National Library of Korea for sharing historical materials with us for this research.

Submitted: June 08, 2021 AEST, Accepted: June 29, 2021 AEST

This is an open-access article distributed under the terms of the Creative Commons Attribution 4.0 International License (CCBY-SA-4.0). View this license's legal deed at https://creativecommons.org/ licenses/by-sa/4.0 and legal code at https://creativecommons.org/licenses/by-sa/4.0/legalcode for more information. 


\section{REFERENCES}

Choi, I. 2010. "The Changes of Electric Car Lines and Urban Space of Gyeongseong during the Japanese Colonial Period.” The Journal of Seoul Studies 41: 31-62.

Choi, I., and J. Kim. 2013. "Problems and Measures of the Public Transportation in Gyeongseong Area in 1930s-1940s.” The Journal of Seoul Studies 50: 145-83. https://doi.org/10.17647/ jss.2013.02.50.145.

Donnellan, L. 2019. "Modeling the Rise of the City: Early Urban Networks in Southern Italy." Frontiers in Digital Humanities 6 (15). https://doi.org/10.3389/fdigh.2019.00015.

Hazareesingh, S. 2001. "Colonial Modernism and the Flawed Paradigms of Urban Renewal: Uneven Development in Bombay, 1900-25.” Urban History 28 (2): 235-55. https://doi.org/ $10.1017 / \mathrm{s} 096392680100205 \mathrm{x}$.

Kawabata, M., and Q. Shen. 2006. "Job Accessibility as an Indicator of Auto-Oriented Urban Structure: A Comparison of Boston and Los Angeles with Tokyo." Environment and Planning B: Planning and Design 33 (1): 115-30. https://doi.org/10.1068/b31144.

Kim, J. 2007. “The Electric Car Issue of the Gyeongseong-Bu Area’s Outskirts during the Japanese Occupation Period, and Local Movement: Examination of the 1932-33 Movement against the Abolishment of the Electric Car Outskirts Line.” The Journal of Seoul Studies 29: 251-78.

Kim, J., and B. Lee. 2019. "More than Travel Time: New Accessibility Index Capturing the Connectivity of Transit Services.” Journal of Transport Geography 78: 8-18. https://doi.org/ 10.1016/j.jtrangeo.2019.05.008.

Lee, J., and H. J. Miller. 2020. "Robust Accessibility: Measuring Accessibility Based on Travelers' Heterogeneous Strategies for Managing Travel Time Uncertainty.” Journal of Transport Geography 86: 102747. https://doi.org/10.1016/j.jtrangeo.2020.102747.

Pereira, R. H. M., M. Saraiva, D. Herszenhut, C. K. V. Braga, and M. W. Conway. 2021. "R5r:

Rapid Realistic Routing on Multimodal Transport Networks with R5 in R.” Findings.

https://doi.org/10.32866/001c.21262.

U.S. Department Transportation. 2021. “GTFS Builder Guidebook.” 2021.

http://nationalrtap.org/Web-Apps/GTFS-Builder. 